\title{
Weibull approach to brake pad wear analysis in the Nigerian market
}

\author{
R. S. FONO-TAMO ${ }^{1, *}$, O. O. OSUNBOR ${ }^{2}$, O. A. KOYA ${ }^{2}$ \\ ${ }^{l}$ Department of Mechanical and Biomedical Engineering, Bells University of Technology, Ota, Nigeria \\ ${ }^{2}$ Department of Mechanical Engineering, Obafemi Awolowo University, Ile-Ife, Nigeria \\ Received: 21 February 2015 / Revised: 15 May 2015 / Accepted: 24 June 2015 \\ (C) The author(s) 2015. This article is published with open access at Springerlink.com
}

\begin{abstract}
In this study, we evaluated the wear properties of four brands of brake pad available in the Nigerian market. In particular, we assessed the tribo performance and service life of the brake pads. We purchased four commercial brands of brake pads used in light duty cars and coded them as AU, SN, TY and SM, respectively. A small piece of the brake pad lining materials was carefully chiseled from the back plates to obtain samples for the experiments. We conducted Brinell hardness tests using a tensometer and a pin-on-disc test rig to determine the coefficient of friction and the wear characteristics of the materials. We then correlated the wear on each set of brake pads with the running time and used Weibull's equation to determine average service life. Sample TY exhibited the highest hardness value (29.09) and sample SN the lowest (10.05). The determined coefficients of friction ranged between 0.3-0.36, with sample AU exhibiting the lowest value and sample SM the highest. Sample SN showed the lowest wear rate of $3.53 \times 10^{9} \mathrm{~g} / \mathrm{min}$, while the wear rates of samples TY, AU, and SM were $5.64 \times 10^{8}, 8.19 \times 10^{9}$, and $2.10 \times 10^{8} \mathrm{~g} / \mathrm{min}$, respectively. The relative service life of samples SN, TY, and AU were similar, with average values of $2778.09,2725.41$, and $2717.34 \mathrm{~min}$, respectively, and SM had a relatively low service life (2017.82 $\mathrm{min})$. We conclude that the overall performances of Nigerian brake pads do not meet all the specifications for friction materials used in road vehicle brake linings and pads.
\end{abstract}

Keywords: Weibull; wear rate; service life; brake pads; friction composite

\section{Introduction}

No two manufactured parts are exactly the same, no matter how carefully they are made. Although the differences may be small, they do exist and have an important bearing on experimental design analysis. Basic statistical tools are also necessary in the design of engineering experiment analysis.

The Weibull distribution is widely used in the field of engineering because of its versatility. Originally proposed for the interpretation of fatigue data, its use has been extended to many other engineering problems. Although the Weibull distribution is applicable to many engineering situations, its principal use is in

*Corresponding author: R. S. FONO-TAMO.

E-mail: ftrromeo@gmail.com the analysis of life data. The real usefulness of the Weibull distribution is its use of straight line plots to represent scattered data.

The Weibull distribution can be applied in situations where the percentage of occurrences may decrease, increase, or remain constant with an increase of the characteristic being measured, such as parts needing repair or wearing out, and the likelihood of failure at various stages of product life. In addition to predicting their lifetime corrosion and overall deterioration, Weibull analysis can be used in product-life test cases of engineering components such as electronic tubes, antifriction bearings, transmission gears, and many other mechanical and electrical components.

The significant effects of wear, particularly in the brake pads of disc brake systems, is the reduction in life span. The greater the wear, the sooner the brake 
pads must be replaced [1]. Investigations of brake-pad wear processes have been conducted primarily experimentally. The wear process is typically evaluated in terms of it wear rate, weight loss, volume loss, and thickness reduction.

A variety of brake pads have been developed [2] and are available commercially, either as original equipment from the manufacturer (OEM) or after-market (replacement) pads. While Weibull distribution has been applied to the analysis of individual brake pad performance, these analyses have not focused on wear.

This paper analyzes the wear characteristics of some commercial brake pads that were purchased randomly using a statistical tool. We subjected samples of the purchased pads to wear experiments and then comparatively analyzed the results using the Weibull distribution approach.

\section{Materials and methods}

\subsection{Hardness test}

To determine the resistance of brake lining material to indentation, we conducted a Brinell hardness test, using a tensometer (Model 10055, Monsanto, UK), by pressing a hardened steel ball into a test specimen. According to ASTM specifications (www.astm.org, 2012), we used a 10-mm diameter ball.

In the tests, the diameter of the ball $D$ was constant at $10 \mathrm{~mm}$, and the load applied $W$ was maintained at $300 \mathrm{~kg}$. The specimen was mounted in the holding device and the ball location was fixed. A hand wheel was rotated so that the ball moved toward the specimen. The desired load was applied mechanically by a gear-driven screw pressing the ball into the specimen. The diameter of the indentation made in the specimen by the pressed ball was then measured using a veneer caliper. The indentation diameter $d$ was measured in two places at right angles to each other, and the average of these two readings was taken. We then calculated the Brinell hardness number (BHN), which is the pressure per unit surface area of the indentation in $\mathrm{kg}$ per square meter, using Eq. (1):

$$
\mathrm{BHN}=\frac{w}{(\pi D / 2)\left(D-\sqrt{\left.D^{2}-d^{2}\right)}\right.}
$$

where $w$ is the load on the indenter in $\mathrm{kg}, d$ is the average measured diameter of indentation in $\mathrm{mm}$, and $D$ is diameter of the steel ball ( $\mathrm{mm})$.

\subsection{Tribological characteristics of the brake pads}

Investigations of the tribological characteristics of the brake pads were conducted using dry friction on a pin-on-disc tester, as shown in Fig. 1. The sample was mounted perpendicularly on a rotating disc and was driven against a steel counterpart that was fixed on a lever mechanism. The coefficient of friction of each sample was determined using the following expression:

$$
\mu=\tan \theta
$$

In this study, we consider two important parameters: load and time. While speed was kept constant at $300 \mathrm{rpm}$, we varied the load from 100 to $500 \mathrm{~g}$ in experimental runs of 10 to $40 \mathrm{~min}$. The wear track formed on the rotating sample was a circle of radius $14 \mathrm{~mm}$, and all parameters were kept constant in each experimental run. We based our method on that used by Rabishankar [3] in the study of the wear behavior of a rice-husk ceramic composite and by Jaykant [4] in the study of the wear properties of carburized mild steel samples.

After each test, we only considered the mass loss of the sample as wear, and this was determined by weighing the specimen before and after the test using a precision electronic scale (Model TB153, SNR 1117220699, Mettler Soledo, Switzerland).

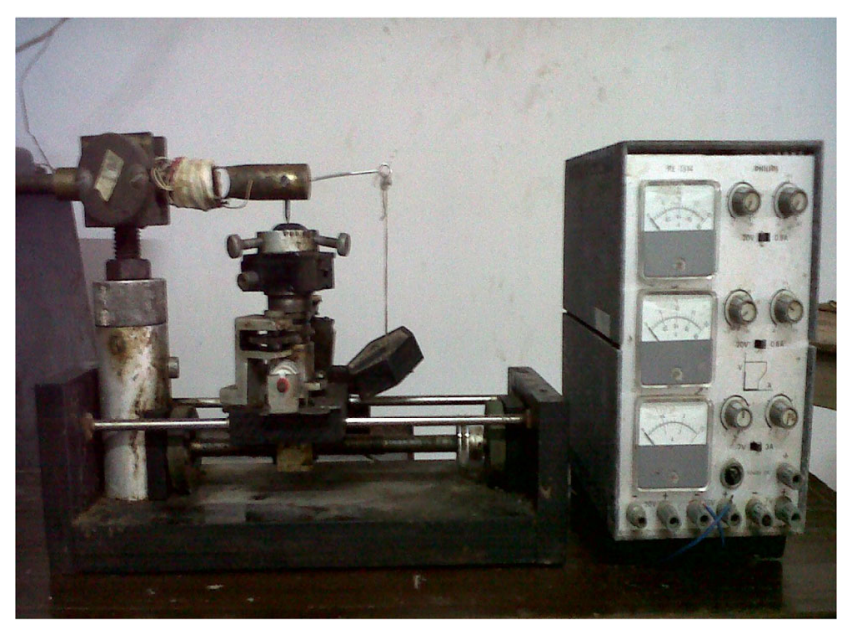

Fig. 1 The pin-on disc wear tester machine. 
The mass loss was then converted to wear volume loss, based on the density of the various commercial brake pad samples. The wear rate was then calculated [5] as

$$
W_{\mathrm{r}}=\frac{W_{\mathrm{v}}}{S_{\mathrm{d}}}
$$

where $W_{\mathrm{r}}$ is the wear rate $(\mathrm{g} / \mathrm{min}), W_{\mathrm{v}}$ is the wear volume, and $S_{\mathrm{d}}$ is the sliding distance $(\mathrm{m})$.

\subsection{Computation of service life}

Next, we used the estimated degrees of wear in the four brake pad samples to project the service life. When the sample had not failed, we estimated the service life [6] as shown in Eq. (4):

$$
T=\frac{t_{1}}{\Delta D} D_{\text {Rest }}+t_{1}
$$

where $T$ is the (life time variable) operating time in minutes, $t_{1}$ is the moment at which the degree of wear was measured, $\Delta D$ is the degree of wear, and $D_{\text {Rest }}$ is the brake pad thickness remaining.

All these variables were used to determine the parameters of the Weibull functions. We derived the expected service life values $(T)$ for the four commercial brake pad samples from the Weibull plots. The Weibull parameters obtained from the plot were then used to predict service life, using Eq. (5):

$$
F(x)=1-\exp \left[-\left(\frac{x-x_{0}}{\theta-x_{0}}\right)^{b}\right]
$$

where $x$ is the expected life projection in days, $x_{0}$ is the assumed lower bound, $\theta$ is the characteristic life, and $b$ is the Weibull slope.

The estimated operating time $(T)$ for each brand of brake pads is an accumulated time, which is a life variable obtained from Eq. (2). We can make an adequate deduction regarding the failure characteristics of the component in question using the Weibull evaluation. Instead, of the mean, the characteristic life $T$, at which $63.2 \%$ of the components fail, is specified from a linearized Weibull distribution. This Weibull analysis approach was also used as a prediction of tensile failure for Kevler-29 fiber materials [7].
In the linearized form:

$$
\ln \left[\ln \left(\frac{1}{1-F(x)}\right)\right]=b \ln \left(x-x_{0}\right)-b \ln \left(\theta-x_{0}\right)
$$

and compared with a linear equation of the form;

$$
\begin{gathered}
y=m x+c \\
b \ln \left(\theta-x_{0}\right)=c \\
\theta=x_{0}+\exp (c / b)
\end{gathered}
$$

where Eq. (6) is the intercept of the linear equation and Eq. (7) is the shape parameter.

According to Roninnger [6], it is well recognized that if:

$b<1$, early-type failures (premature failures), e.g., due to production/assembly faults, will prevail;

$b=1$, chance-type failures (random failures) and a constant failure rate, with no connection to the actual life characteristic, will prevail;

$1<b>1.4$, time-dependent (aging effect) failures within the design period will prevail.

\section{Results and discussion}

\subsection{Hardness test result}

The BHN values for the four brake pad samples are shown in Table 1. Statistical analysis results (Table 2) for the four experimental samples, using one-way analysis of variance (ANOVA), shows significant difference samong the four samples at $p \leqslant 0.05$. Evidently, only the TY samples meet the Standards Organization of Nigeria (SON) recommendation of a BHN of at least 27 (NIS 323, 1997).

\subsection{Tribological behavior of the brake pads}

Based on the obtained coefficients of friction shown in Table 1, the sample SM friction composite has a higher coefficient of friction on mild steel, in the 0.36 range, compared to those of samples $\mathrm{AU}, \mathrm{SE}$, and TY, which are within the 0.30 to 0.35 range. These values are in good agreement with SON specifications, which recommend a friction coefficient of at least 0.3 . Therefore, the four commercial friction linings meet this SON specification. 
Table 1 Physical-mechanical properties of the sampled brake pads.

\begin{tabular}{|c|c|c|c|c|c|c|}
\hline \multirow{2}{*}{ Test } & \multirow{2}{*}{ Sample size } & \multicolumn{5}{|c|}{ Brands } \\
\hline & & TY & $\mathrm{AU}$ & SN & SM & $\mathrm{SON}^{+}$ \\
\hline $\mathrm{BHN}$ & 3 & $\begin{array}{c}29.09 \\
(1.79)^{*}\end{array}$ & $\begin{array}{l}22.31 \\
(0.98)\end{array}$ & $\begin{array}{l}10.05 \\
(2.30)\end{array}$ & $\begin{array}{l}15.24 \\
(0.88)\end{array}$ & $\leqslant 27$ \\
\hline Friction coefficient on steel & 3 & $\begin{array}{c}0.35 \\
(0.14)\end{array}$ & $\begin{array}{c}0.30 \\
(0.30)\end{array}$ & $\begin{array}{c}0.31 \\
(0.24)\end{array}$ & $\begin{array}{c}0.36 \\
(0.20)\end{array}$ & $\leqslant 0.3$ \\
\hline Average wear rate $(\mathrm{g} / \mathrm{min})$ & 5 & $\begin{array}{c}5.64 \times 10^{8} \\
(0.0008)\end{array}$ & $\begin{array}{c}8.19 \times 10^{9} \\
(0.0008)\end{array}$ & $\begin{array}{c}3.53 \times 10^{9} \\
(0.0078)\end{array}$ & $\begin{array}{c}2.10 \times 10^{8} \\
(0.0047)\end{array}$ & \\
\hline
\end{tabular}

* Numbers in parenthesis are the standard deviations. $\mathrm{SON}^{+}$: Standard Organization of Nigeria.

Table 2 Multiple comparisons of the BHN values of the four commercial brake pads.

\begin{tabular}{cccccc}
\hline \multirow{2}{*}{ Pad type (I) } & \multirow{2}{*}{ Pad type (J) } & Mean difference (I-J) & Significance & \multicolumn{2}{c}{$95 \%$ confidence interval } \\
\cline { 4 - 5 } & & & & Lower bound & Upper bound \\
\hline \multirow{2}{*}{ AU } & SN & $12.2733333^{*}$ & 0.000 & 8.100270 & 16.446397 \\
& TY & -6.7800000 & 0.004 & -10.953063 & -2.606937 \\
& SM & 7.0666667 & 0.003 & 2.893603 & 11.239730 \\
\multirow{2}{*}{ SN } & AU & -12.2733333 & 0.000 & -16.446397 & -8.100270 \\
& TY & -19.0533333 & 0.000 & -23.226397 & -14.880270 \\
& SM & -5.2066667 & 0.017 & -9.379730 & -1.033603 \\
\multirow{2}{*}{ TY } & AU & 6.7800000 & 0.004 & 2.606937 & 10.953063 \\
& SN & 19.0533333 & 0.000 & 14.880270 & 23.226397 \\
& SM & 13.8466667 & 0.000 & 9.673603 & 18.019730 \\
\multirow{2}{*}{ SM } & AU & -7.0666667 & 0.003 & -11.239730 & -2.893603 \\
& SN & 5.2066667 & 0.017 & 1.033603 & 9.379730 \\
& TY & -13.8466667 & 0.000 & -18.019730 & -9.673603 \\
\hline
\end{tabular}

The average wear, as presented in Table 1 for the 5 sample specimens, shows that sample SN had the lowest wear rate of $3.53 \times 10^{9} \mathrm{~g} / \mathrm{min}$, while samples TY, AU, and SM had rates of $5.64 \times 10^{8}, 8.19 \times 10^{9}$, and $2.10 \times 10^{8} \mathrm{~g} / \mathrm{min}$, respectively. We estimated the wear rates of the four commercial brake pads under different loads from the slope of the wear plotted against time. The four brake pads showed different wear rate trends (in $\mu \mathrm{g} / \mathrm{min}$ in Table 3) under different loads. For a $100 \mathrm{~g}$ load, the wear rate of sample SM (0.02) was lower than that of SN and TY, and higher than that of AU. As load increased from 200-500 g, AU showed the least rate of wear (0.16) at $400 \mathrm{~g}$, and the highest wear rate was observed at $500 \mathrm{~g}$ in sample SN. Statistical analysis results show that the mean wear rates of the four experimental brake pads are not significant at the $\alpha=0.01$ confidence level with $p \leqslant 0.52$. The correlation of the wear of the four commercial brake pads $(Y)$

Table 3 Wear rates for the four commercial brake pads from the polynomial curves.

\begin{tabular}{ccccc}
\hline \multirow{2}{*}{ Load $(\mathrm{g})$} & \multicolumn{4}{c}{ Wear rates $(\mu \mathrm{g} / \mathrm{min})$} \\
\cline { 2 - 5 } & TY & AU & SN & SM \\
\hline 100 & 79.9 & 4,086 & 59.9 & 0.02 \\
200 & 400 & 1.97 & 11.07 & 1.10 \\
300 & 2,000 & 2.33 & 2.26 & 2.93 \\
400 & 140 & 0.16 & 162.99 & 10,500 \\
500 & 200 & 2.69 & 17,400 & 2.2 \\
\hline
\end{tabular}


with time $(X)$ is a third-order polynomial curve, as shown in Figs. 2-5, and the corresponding coefficients of determination $r^{2}$ are shown in Table 4, with their corresponding equations for the most significant values of $r^{2}$.

\subsection{Predicted characteristic life based on Weibull analysis}

The calculated results of the expected service life of the four brake pad samples in this study were projected from their degree of wear using Eq. (5). Based on the

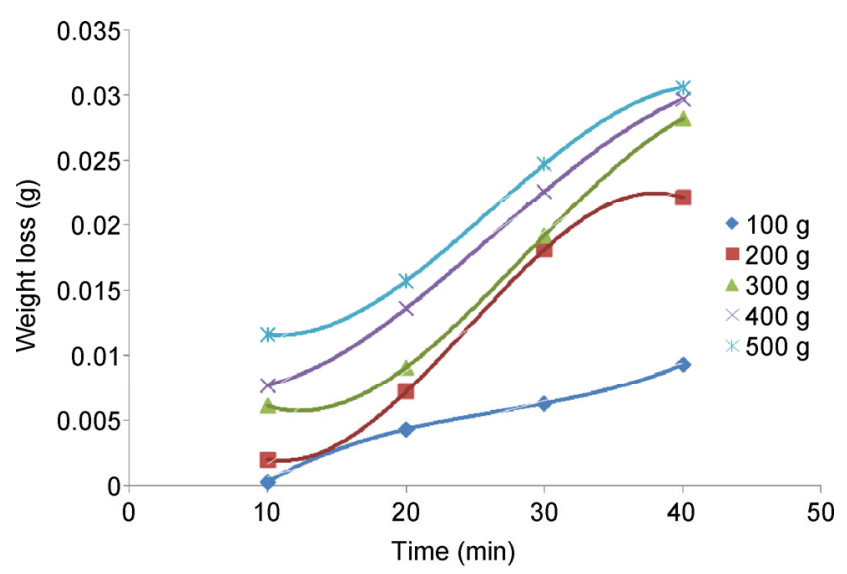

Fig. 2 Weight loss against time for sample TY.

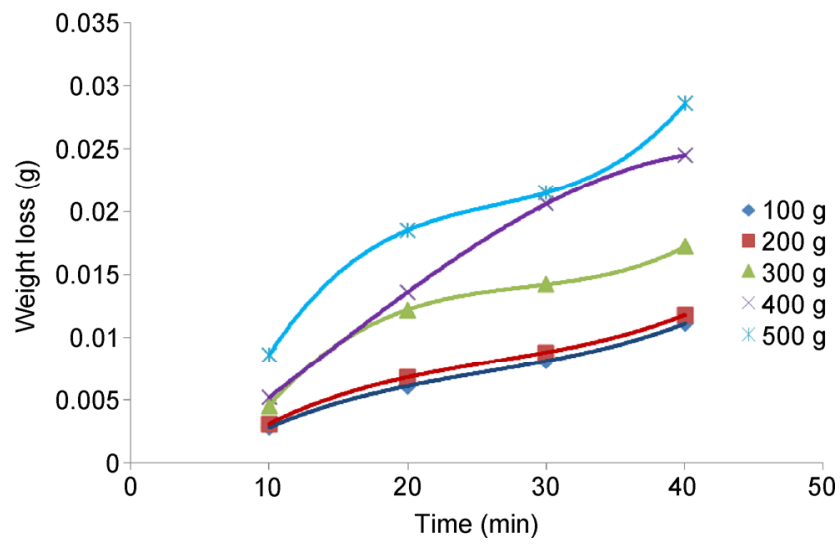

Fig. 3 Weight loss against time for sample SN. test results, the relative service lives of samples TY, SN, and AU are similar, with values of 2725.41, 2778.09 and $2717.34 \mathrm{~min}$; while the expected service life of sample SM was lowest (2017.82 $\mathrm{min}$ ). This shows that the AU sample will last longer than samples SM, SN, and TY in identical field applications. However, the actual service life of the friction composites must be determined in drag tests using inertial dynamometers (full-scale and sub-scale hardware) and laboratory tribometers in tests involving programmed changes in contact pressure, speed, temperature, and repetitive contacts to simulate vehicle braking events (SAE J 1652). These facilities were not available for this study.

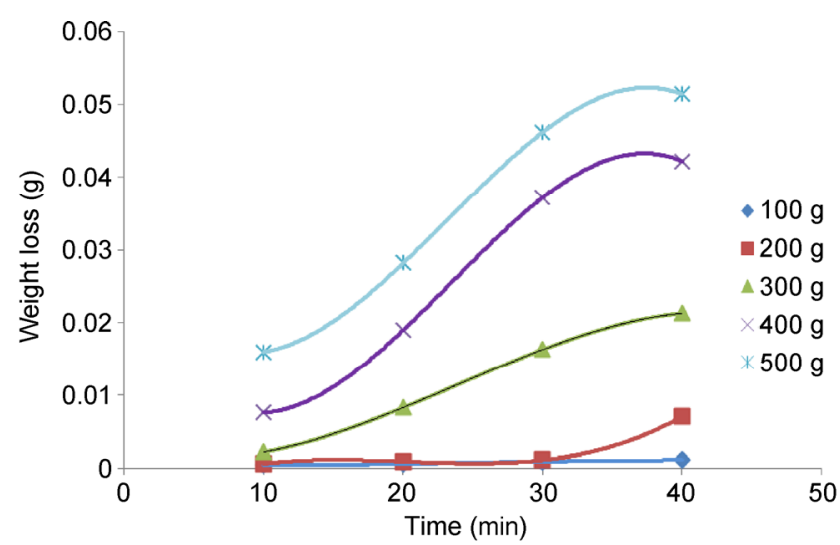

Fig. 4 Weight Loss against Time for Sample SM.

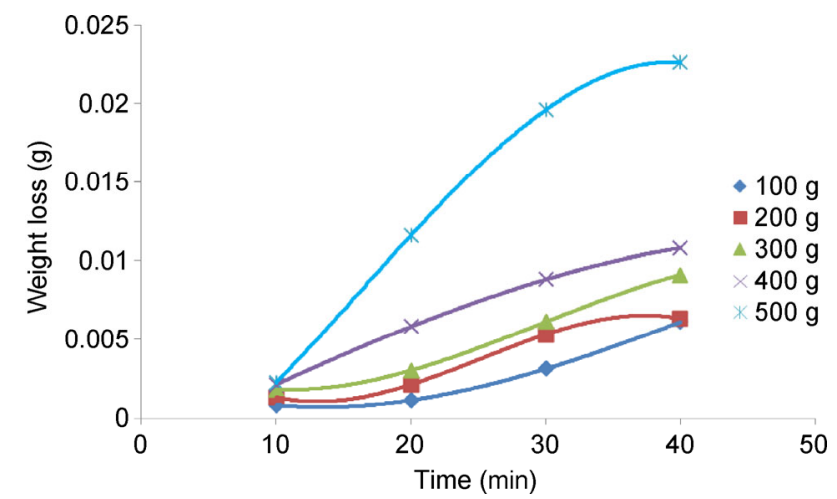

Fig. 5 Weight Loss against Time for Sample AU.

Table 4 Correlation of weight loss and loading time for the commercial brake pads.

\begin{tabular}{cccc}
\hline Brand & Load $(\mathrm{g})$ & Equation & Correlation coefficient $\left(r^{2}\right)$ \\
\hline AU & 400 & $\mathrm{Y}=-5 \times 10^{-8} x^{3}-5 \times 10^{-5} x^{2}+0.0004 x-0.002$ & 0.9999 \\
$\mathrm{SN}$ & 400 & $\mathrm{Y}=-3 \times 10^{-7} x^{3}+1 \times 10^{-5} x^{2}+0.0007 x-0.0029$ & 0.9993 \\
$\mathrm{TY}$ & 400 & $\mathrm{Y}=-8 \times 10^{-7} x^{3}+7 \times 10^{-5} x^{2}-0.0008 x+0.0099$ & 0.9943 \\
$\mathrm{SM}$ & 300 & $\mathrm{Y}=-8 \times 10^{-7} x^{3}+6 \times 10^{-5} x^{2}-0.0006 x+0.0029$ & 0.9944 \\
\hline
\end{tabular}




\section{Conclusion}

In this study, we examined the physical-mechanical and tribological characteristics of some locally available brake pads in Nigeria to gain a better understanding of the tribo performance of Nigerian brake pads. From the analysis results, we can make the following conclusions: sample TY exhibited the highest hardness value (29.09) and sample SN the lowest (10.05). The determined coefficient of friction of the samples ranged from 0.3-0.36, with sample AU exhibiting the lowest value and sample SM the highest. The brake pads exhibited different wear rates, ranging from $3.53 \times 10^{9}-5.64 \times 10^{8} \mathrm{~g} / \mathrm{min}$ as load increased, and relative characteristic lives ranging from 2017.82-2778.09 min of operation against a hardened steel surface.

Consequently, the study results revealed that the overall experimental performance of Nigerian brake pads do not meet all the standard specifications recommended by SON for friction materials in road vehicle brake linings and pads (NIS 323).

We recommend that appropriate machinery be installed according to the Standards Organization of Nigeria to counter the proliferation of substandard brake pads in the Nigerian marketplace.

\section{Acknowledgement}

The authors appreciate the assistance of the technical staffs at the Tribology Laboratory of the Department of

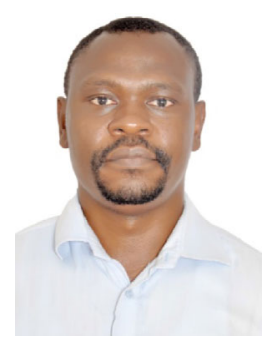

R. S. FONO-TAMO. He received his BS and MS degrees in mechanical engineering in 2006 and 2009 respectively from Obafemi Awolowo University, Ile-Ife, Nigeria. He continued in the same Institution as a Ph.D student while being a lecturer
Material Science and Engineering, Obafemi Awolowo University, Ile-Ife, Nigeria.

Open Access: This article is distributed under the terms of the Creative Commons Attribution License which permits any use, distribution, and reproduction in any medium, provided the original author(s) and source are credited.

\section{References}

[1] Abu-Bakar A B, Ouyang H, James S, Li L. Finite element analysis of wear and its effect on squeal generation. Proc IMechE, Part D: J Aut Eng 222: 1153-1165 (2007)

[2] Fono-Tamo R S. A study on the use of palm kernel shell as friction material in automotive brake pads and lining. MS Thesis. Ile-Ife (Nigeria): Obafemi Awolowo University, 2009.

[3] Rabishankar. Study of wear behaviour of rice husk ceramic composites. BTech Thesis. Rourkela (India): National Institute of Technology, 2010.

[4] Jaykant G. Mechanical and wear properties of carburized mild steel samples. MTech Thesis. Rourkela (India): National Institute of Technology, 2009.

[5] Aigbodion V S, Akadike U, Asuke F, Agunsoye J O, Hassan S B. Development of asbestos-Free brake pad using bagasse. Tribology in Industry 32 (1): 12-17 (2010)

[6] Roninnger C U. Reliability Analyses with Weibull. 11th edition. www.crgraph.com, 2010: 36-71.

[7] Newell A J, Sagendorf M T. Experimental verification of the end-effect Weibull model as a predictor of tensile strength of Kevlar-29 fibres. High Performance Polymer 11: 297-305 (1999)

in the Department of Mechanical and Biomedical Engineering, Bells university of Technology Ota, Nigeria. He recently received his Ph.D degree in mechanical engineering. His research interests include biotribology, characterization of agricultural wastes for engineering application, composite materials, alloy materials, and computer simulation. 